\title{
Electrical percolation through a discontinuous Au nanoparticle film
}

Cite as: Appl. Phys. Lett. 112, 251602 (2018); https://doi.org/10.1063/1.5023163

Submitted: 22 January 2018 . Accepted: 01 June 2018 . Published Online: 20 June 2018

Merel J. Lefferts, Krishnan Murugappan, Chen Wu, and Martin R. Castell (D)

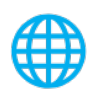

\section{ARTICLES YOU MAY BE INTERESTED IN}

Percolation theory based statistical resistance model for resistive random access memory Applied Physics Letters 112, 253505 (2018); https://doi.org/10.1063/1.5023196

Optically transparent wideband CVD graphene-based microwave antennas Applied Physics Letters 112, 251103 (2018); https://doi.org/10.1063/1.5037409

Structured ultrasound microscopy

Applied Physics Letters 112, 251901 (2018); https://doi.org/10.1063/1.5026863

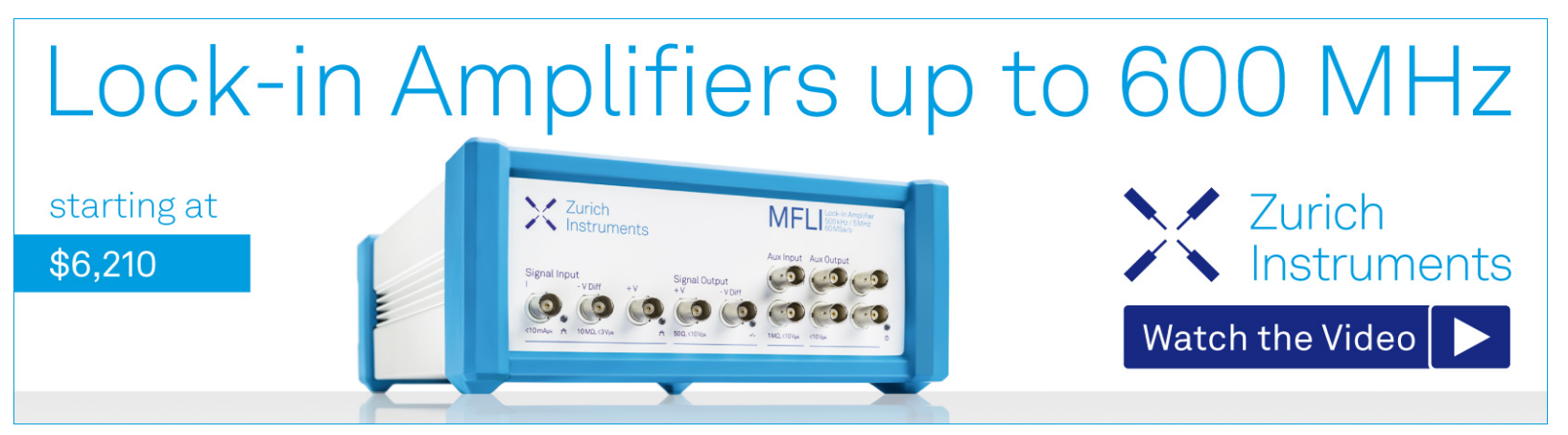




\title{
Electrical percolation through a discontinuous Au nanoparticle film
}

\author{
Merel J. Lefferts, ${ }^{\text {a) }}$ Krishnan Murugappan, Chen Wu, ${ }^{\text {b) }}$ and Martin R. Castell ${ }^{\mathrm{c})}$ \\ Department of Materials, University of Oxford, Parks Road, Oxford OXI 3PH, United Kingdom
}

(Received 22 January 2018; accepted 1 June 2018; published online 20 June 2018)

\begin{abstract}
Au thin films of thicknesses ranging from 5 to $20 \mathrm{~nm}$ were grown in UHV through physical vapour deposition on glass substrates decorated with Pt interdigitated electrodes with $5 \mu \mathrm{m}$ separation. As expected, a gradual decrease in the electrical resistance of the films was observed as growth proceeded; however, when the average film thickness was greater than around $11 \mathrm{~nm}$, the resistance decrease was not smooth but occurred in discrete steps. These resistance steps are attributed to the formation of electrical percolation pathways connecting the electrodes. The samples were then annealed at temperatures between $200{ }^{\circ} \mathrm{C}$ and $500{ }^{\circ} \mathrm{C}$ for periods of 1 to $22 \mathrm{~h}$ with the aim of producing insulating nanoparticle films. Dewetting of the Au films produces nanoparticles whose size and separation depend on annealing temperature and time, as well as the initial thickness of the Au film. The complex electrical resistance behaviour of the film was also monitored during the dewetting process. Published by AIP Publishing. https://doi.org/10.1063/1.5023163
\end{abstract}

Creating a film or network close to the percolation threshold can play an important role in applications related to energy storage, ${ }^{1,2}$ medicine, ${ }^{3-5}$ Raman scattering, ${ }^{6}$ and transparent electrodes. ${ }^{7}$ There are various methods to synthesise nanoparticle films, such as chemical deposition, ${ }^{8}$ ultrasonic spray pyrolysis, ${ }^{9}$ and electrochemical techniques. ${ }^{10}$ One method to gain control over electrical percolation through a metal film is by controlling the wetting behaviour of the film. Creating a discontinuous film through the dewetting of a metal thin film is an especially promising method because at some stage of the dewetting process a discontinuous film or sub-monolayer of particles is created. This technique can be applied to a large range of materials. ${ }^{11-14}$ Furthermore, methods to increase control over the dewetting and the particle size and separation, using sacrificial layers, have been demonstrated. ${ }^{15,16}$

Whether one material wets another material depends on the relative surface and interface energies of the materials. For a liquid on a surface, this is described by the Young-Laplace equation. Describing the wetting of a solid particle on a substrate is more involved because of the anisotropy of crystalline particles. ${ }^{17}$ To create supported metal nanoparticles through dewetting, a metal film is deposited. Next, the film is heated to encourage dewetting. The deposited film is stable if the surface energy of the substrate is larger than that of the interface and the film combined. In all other cases, the system will dewet into individual islands if enough thermal energy is supplied to allow diffusion. Dewetting can take place at temperatures well below the melting point of the metal. ${ }^{18}$

Here, we report the changes in resistance measured in situ during the deposition and annealing of $\mathrm{Au}$ thin films. Resistance changes and conduction mechanisms during thin film deposition have previously been reported for $\mathrm{Ag}, \mathrm{Pt}$, and Pd films amongst others. ${ }^{19-23}$ We also report the resistance changes in sufficient detail to observe stepwise changes in the percolation region. Furthermore, we demonstrate control over

\footnotetext{
a)merel.lefferts@materials.ox.ac.uk

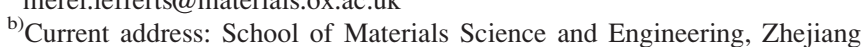
University, Hangzhou 310027, China

c) martin.castell@materials.ox.ac.uk
}

the size and the separation of the resulting gold nanoparticles, without the need for additional materials. The deposition, annealing, and resistance measurements were conducted in ultrahigh vacuum (UHV), ensuring that effects due to contamination were minimised.
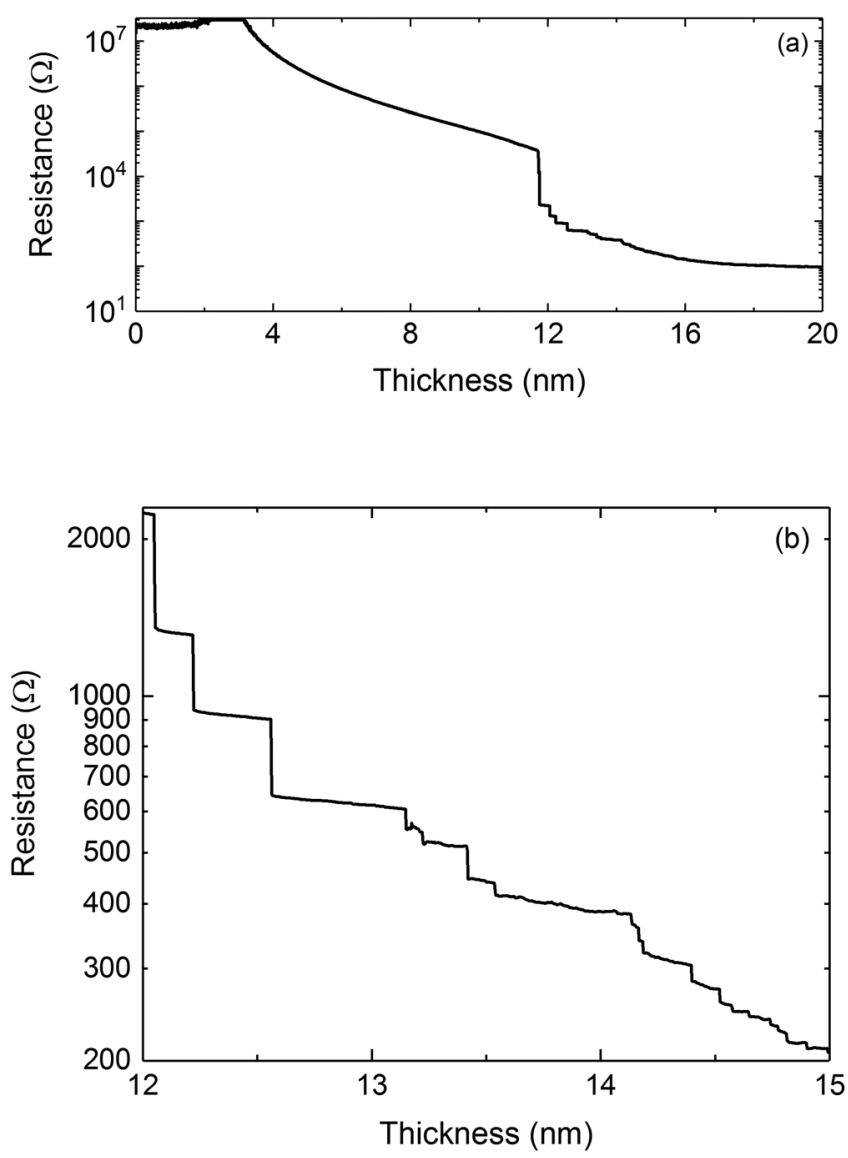

FIG. 1. (a) A typical resistance measurement during the deposition of a $20 \mathrm{~nm}$ thick Au layer. (b) Magnified section of (a) showing stepwise change in resistance during deposition and decreasing step size with increasing $\mathrm{Au}$ layer thickness. 
Au was deposited on glass substrates with Pt interdigitated electrodes (IDEs) with $5 \mu \mathrm{m}$ electrode separation. The narrow electrode separation makes it possible to observe small changes in resistance during Au deposition of very thin films. The IDEs were purchased from DropSens and cleaned with concentrated nitric acid prior to Au deposition. 5, 8, 10, 15, and $20 \mathrm{~nm}$ thick Au films were deposited at $0.2-0.3 \AA / \mathrm{s}$ using a Knudsen-cell in a UHV chamber with a base pressure of $10^{-8} \mathrm{~Pa}$. It should be noted that, due to radiative heat from the $\mathrm{K}$-cell, the substrate was not at room temperature during $\mathrm{Au}$ deposition. The average Au layer thickness was monitored during deposition using a quartz crystal microbalance (QCM). The resistance of the Au layer was monitored in situ by applying $1 \mathrm{~V}$ and measuring the current through the sample. Scanning electron microscopy (SEM) of the samples was performed on a Zeiss Merlin at $3 \mathrm{kV}$.

In general, increasing the Au film thickness causes a gradual decrease in resistance, from approximately $10 \mathrm{M} \Omega$ to $10 \Omega$. A resistance decrease from approximately $10 \mathrm{M} \Omega$ to $100 \Omega$, during the deposition of $20 \mathrm{~nm}$ of $\mathrm{Au}$, is shown in Fig. 1(a). This is to be expected and is in agreement with previous results for thicker films. ${ }^{19,20}$ However, for film thicknesses greater than $\sim 11 \mathrm{~nm}$, the resistance change occurred in discrete steps, instead of a smooth change [Fig. 1(b)]. In the scientific literature, three regimes with their own conduction mechanisms are described: tunneling mechanisms before the percolation threshold, conduction through newly formed pathways around the percolation threshold, and metallic conduction similar to that of a continuous film after the percolation threshold. ${ }^{24,25}$ The resistance steps observed here are attributed to conduction through newly formed electrical pathways that connect the electrodes as more $\mathrm{Au}$ is added to the film, increasing the two-dimensional fill factor of Au on the substrate. Furthermore, the step size decreases with increasing Au layer thickness. The decreasing step size is attributed to the first electrical pathways that are created between the electrodes having a much larger effect on the overall resistance of the Au layer rather than connections that are added when the layer already contains many conductive pathways. The elongated geometry between our IDEs, compared to the more square geometry used in most existing Monte Carlo studies, makes it more likely that multiple completely separated conductive pathways are formed in our experiments. This could explain why stepwise conductance changes are observed here experimentally, but not in existing Monte Carlo studies. ${ }^{26-28}$

To increase the nanoparticle separation and shift the $\mathrm{Au}$ layer back towards the percolation threshold, the deposited $\mathrm{Au}$ layers were annealed using a heater located under the sample. The heating current was slowly ramped up until the desired temperature was reached. The 5, 8, and $10 \mathrm{~nm}$ thick Au films were held at $200{ }^{\circ} \mathrm{C}$ for 1,2 , and $16 \mathrm{~h}$, respectively.
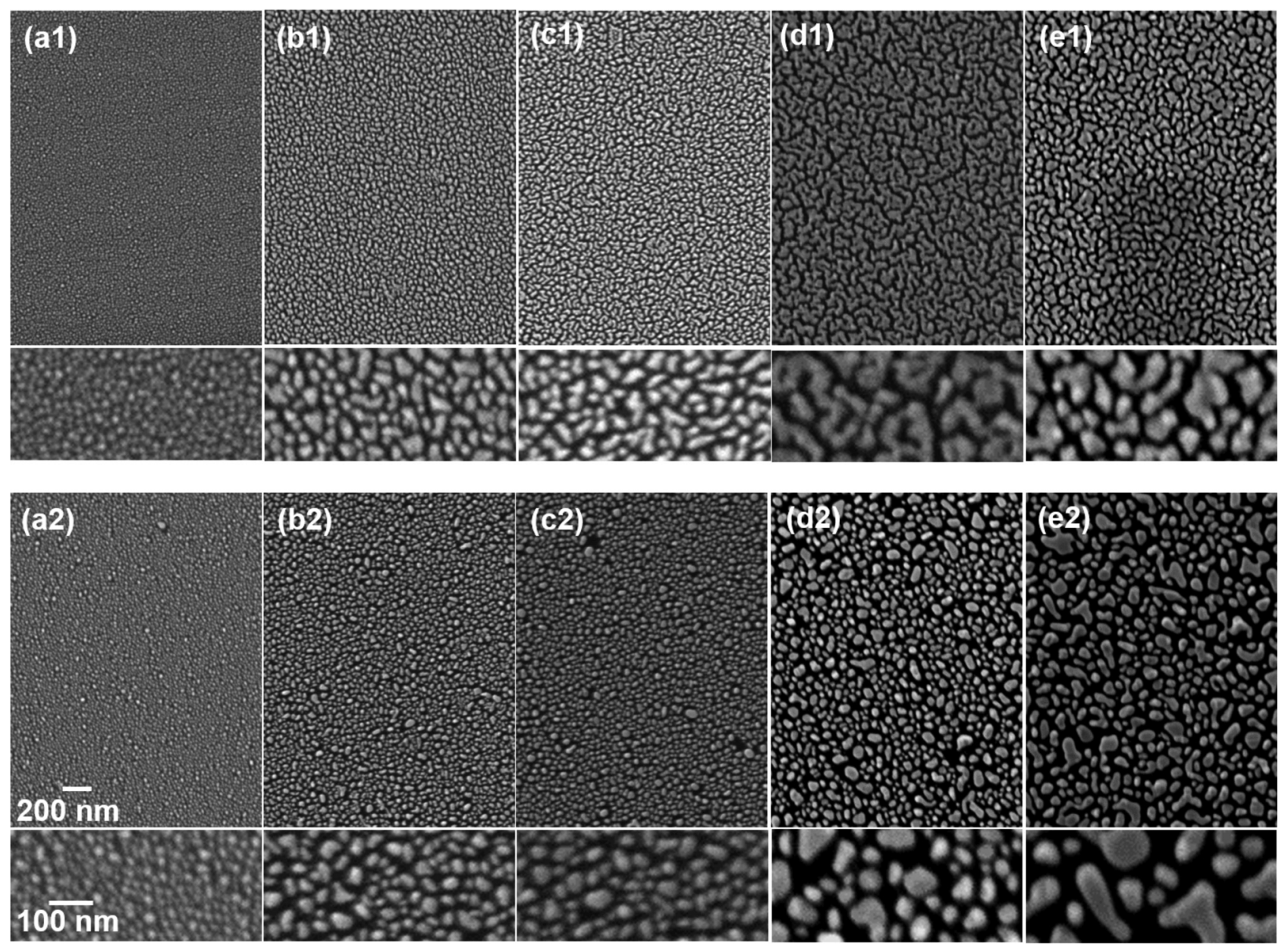

FIG. 2. SEM images of Au deposited on glass substrates, for Au layer thicknesses of (a1) $5 \mathrm{~nm}$, (b1) $8 \mathrm{~nm}$, (c1) $10 \mathrm{~nm}$, (d1) $15 \mathrm{~nm}$, and (e1) $20 \mathrm{~nm}$, as deposited. And, SEM images of the same Au layer thicknesses after annealing, to increase the resistance of the film, at $200{ }^{\circ} \mathrm{C}$ for $1 \mathrm{~h}(\mathrm{a} 2), 2 \mathrm{~h}(\mathrm{~b} 2)$, and $16 \mathrm{~h}$ (c2), and at $350^{\circ} \mathrm{C}$ for $16 \mathrm{~h}$ followed by $500^{\circ} \mathrm{C}$ for $2 \mathrm{~h}(\mathrm{~d} 2)$ and $6 \mathrm{~h}(\mathrm{e} 2)$. A magnified section is given below each image. 


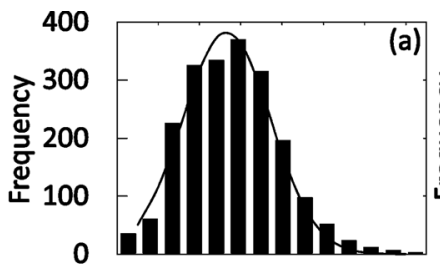

$\begin{array}{lllll}5 & 20 & 35 & 50 & 65\end{array}$ Diameter (nm)

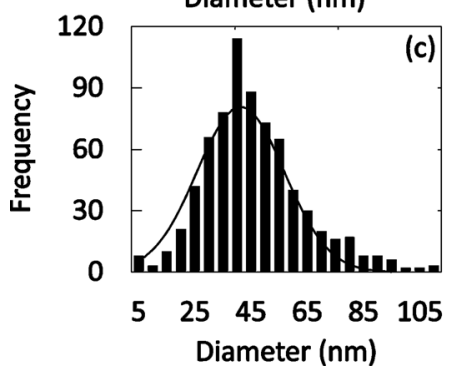

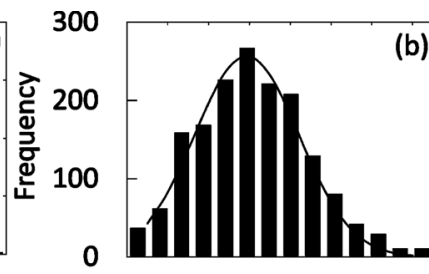

$\begin{array}{lllll}5 & 20 & 35 & 50 & 65\end{array}$ Diameter $(\mathrm{nm})$

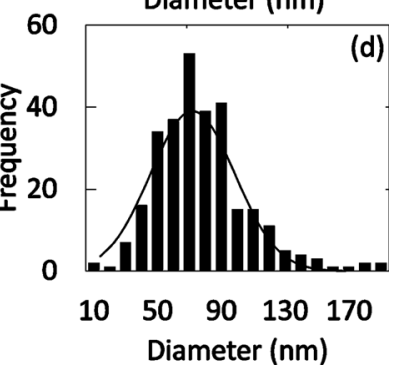

(b)

d)
FIG. 3. Particle size distributions after annealing (a) $8 \mathrm{~nm}$, (b) $10 \mathrm{~nm}$, (c) $15 \mathrm{~nm}$, and (d) $20 \mathrm{~nm}$ thick Au layers at $200^{\circ} \mathrm{C}$ for $2 \mathrm{~h}$, at $200^{\circ} \mathrm{C}$ for $16 \mathrm{~h}$, at $350^{\circ} \mathrm{C}$ for $16 \mathrm{~h}$ followed by $500^{\circ} \mathrm{C}$ for $2 \mathrm{~h}$, and at $350^{\circ} \mathrm{C}$ for $16 \mathrm{~h}$ followed by $500^{\circ} \mathrm{C}$ for $6 \mathrm{~h}$, respectively.

The 15 and $20 \mathrm{~nm}$ thick Au films were held at $350^{\circ} \mathrm{C}$ for $16 \mathrm{~h}$, after which the temperature was increased and held at $500{ }^{\circ} \mathrm{C}$ for 2 and $6 \mathrm{~h}$, respectively. Different annealing temperatures and durations were required to produce insulating nanoparticle films out of films with different thicknesses because the total thermal energy required to dewet Au films depends on the film thickness. ${ }^{29}$

The SEM images in Fig. 2 show that both before and after annealing samples with less $\mathrm{Au}$ on them have smaller particles than samples with more Au. This is in agreement with expectations because to accommodate the larger amount of $\mathrm{Au}$ while maintaining the same wetting angle thicker films result in larger particles. After Au deposition, the samples were annealed to create insulating nanoparticle films. A comparison of SEM images taken before and after annealing shows that, in addition to increasing the resistance, annealing promotes the formation of individual particles and increases the particle separation. The average particle sizes for annealed $8,10,15$, and $20 \mathrm{~nm}$ thick gold layers were $27 \pm 11,29 \pm 13,44 \pm 18$, and $74 \pm 29 \mathrm{~nm}$, respectively, as determined by analyzing the SEM images in Fig. 2 under the assumption that the particles on average are circular (Fig. 3).

After demonstrating the stepwise resistance change during $\mathrm{Au}$ deposition, a similar stepwise change, but in the reverse direction, would be expected during the annealing process of an Au layer. Annealing causes the film to dewet, which decreases the two-dimensional fill factor of the layer. The film becomes less well connected, resulting in an increase in resistance. However, monitoring the resistance during annealing over a similarly large resistance range is more challenging and would require a higher annealing temperature than can be achieved without affecting the glass substrates. Despite it not being possible to dewet the films over the full resistance range, stepwise resistance changes were observed during the initial phase of annealing of the thicker films (Fig. 4). It was observed that during annealing the resistance of the film initially decreases, after which it

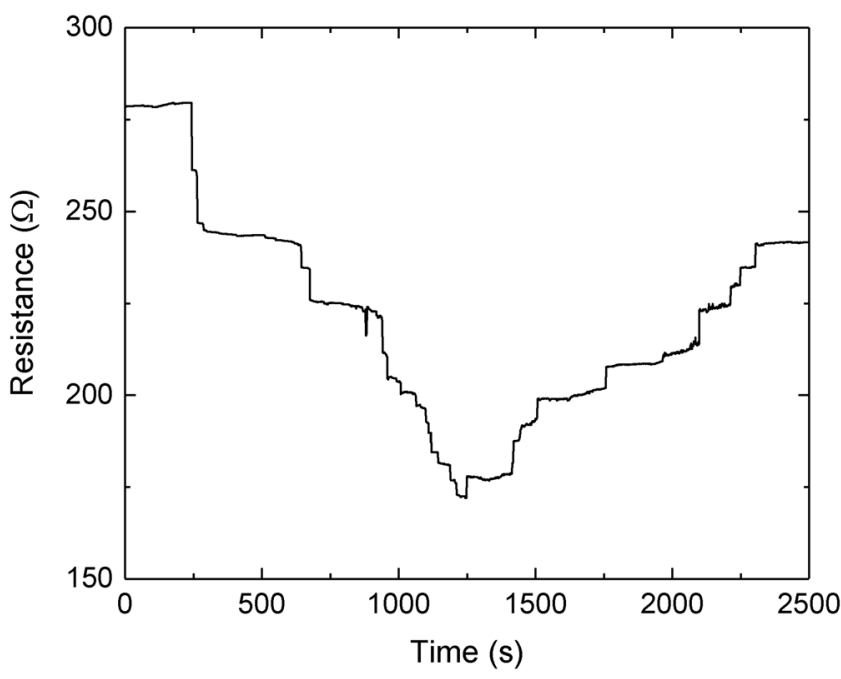

FIG. 4. Resistance of a $20 \mathrm{~nm}$ thick Au layer on glass during the initial $2500 \mathrm{~s}$ of the anneal at $350{ }^{\circ} \mathrm{C}$. An initial decrease in resistance is observed, possibly due to grain growth and the elimination of vacancies, before the resistance increases due to dewetting of the Au layer.

starts to increase. This suggests that the film initially becomes a more ordered, more conductive layer, as is described in the scientific literature for various materials,${ }^{30,31}$ possibly through grain growth and the elimination of vacancies before it starts to dewet.

In conclusion, discontinuous $\mathrm{Au}$ films were formed on glass substrates in a UHV environment. The electrical resistance of the layer as well as the size and the separation of the particles were controlled through the Au film thickness and the annealing temperature and duration. The resistance of the Au layer was monitored in situ during deposition and annealing. Apart from an overall decrease in resistance with increasing film thickness, stepwise changes due to electrical connections being formed in the discontinuous layer were observed. These effects are also expected to be found for other noble metals such as Pt and Pd, provided that the relative surface and interface energies of the metal and the substrate allow for dewetting. Our results open up opportunities for various applications of discontinuous metal films.

This work was supported by Dstl under Contract No. DSTLX-1000081077. We thank Matthew Brookes and Peter Hickey at Dstl for support and insightful comments.

${ }^{1}$ S. S. Mao, S. Shen, and L. Guo, Prog. Nat. Sci.-Mater. 22, 522 (2012).

${ }^{2}$ Y. Jiang, P. Wang, X. Zang, Y. Yang, A. Kozinda, and L. Lin, Nano Lett. 13, 3524 (2013).

${ }^{3}$ G. Doria, J. Conde, B. Veigas, L. Giestas, C. Almeida, M. Assunção, J. Rosa, and P. V. Baptista, Sensors 12, 1657 (2012).

${ }^{4}$ A. R. Schmidt, N. D. Nguyen, and M. C. Leopold, Langmuir 29, 4574 (2013).

${ }^{5}$ M. Holzinger, A. Le Goff, and S. Cosnier, Front. Chem. 2, 63 (2014).

${ }^{6}$ F. Brouers, S. Blacher, A. Lagarkov, A. K. Sarychev, P. Gadenne, and V. M. Shalaev, Phys. Rev. B 55, 13234 (1997).

${ }^{7}$ A. Kumar and G. Kulkarni, J. Appl. Phys. 119, 015102 (2016).

${ }^{8}$ S. R. Ahmed, J. Kim, T. S. Van Tan Tran, S. Neethirajan, J. Lee, and E. Y. Park, Sci. Rep. 7, 11 (2017).

${ }^{9}$ M. de la Garza, I. López, and I. Gómez, Adv. Mater. Sci. Eng. 2013, 5 (2013). 
${ }^{10}$ X. Dai and R. G. Compton, Anal. Sci. 22, 567 (2006).

${ }^{11}$ C. T. Campbell, Surf. Sci. Rep. 27, 1 (1997).

${ }^{12}$ C. R. Henry, Prog. Surf. Sci. 80, 92 (2005).

${ }^{13}$ H. Sato and S. Shinozaki, J. Vac. Sci. Technol. 8, 159 (1971).

${ }^{14}$ F. Silly and M. R. Castell, Appl. Phys. Lett. 87, 063106 (2005).

${ }^{15}$ A. Sundar, R. A. Hughes, P. Farzinpour, K. D. Gilroy, G. A. Devenyi, J. S. Preston, and S. Neretina, Appl. Phys. Lett. 100, 013111 (2012).

${ }^{16}$ P. Farzinpour, A. Sundar, K. D. Gilroy, Z. E. Eskin, R. A. Hughes, and S. Neretina, Nanotechnology 23, 495604 (2012).

${ }^{17}$ W. Winterbottom, Acta Metall. 15, 303 (1967).

${ }^{18}$ C. V. Thompson, Annu. Rev. Mater. Res. 42, 399 (2012).

${ }^{19}$ K. L. Chopra, L. C. Bobb, and M. H. Francombe, J. Appl. Phys. 34, 1699 (1963).

${ }^{20}$ M. Adamov, B. Perović, and T. Nenadović, Thin Solid Films 24, 89 (1974).

${ }^{21}$ H. Wei and H. Eilers, J. Phys. Chem. Solids 70, 459 (2009).
${ }^{22}$ E. Dobierzewska-Mozrzymas, E. Pieciul, P. Bieganski, and G. Szymczak, Cryst. Res. Technol. 36, 1137 (2001).

${ }^{23}$ S. Wagner and A. Pundt, Phys. Rev. B 78, 155131 (2008).

${ }^{24}$ K.-H. Müller and M. Yajadda, J. Appl. Phys. 111, 123705 (2012).

${ }^{25}$ V. Sabayev, N. Croitoru, A. Inberg, and Y. Shacham-Diamand, Mater. Chem. Phys. 127, 214 (2011).

${ }^{26}$ Y. Yuge and K. Onizuka, J. Phys. C Solid State 11, L763 (1978).

${ }^{27}$ P. Bruschi, P. Cagnoni, and A. Nannini, Phys. Rev. B 55, 7955 (1997).

${ }^{28}$ T. Coutts and B. Hopewell, Thin Solid Films 9, 37 (1972).

${ }^{29}$ P. R. Gadkari, A. P. Warren, R. M. Todi, R. V. Petrova, and K. R. Coffey, J. Vac. Sci. Technol. A 23, 1152 (2005).

${ }^{30}$ S. Sun, C. B. Murray, D. Weller, L. Folks, and A. Moser, Science 287, 1989 (2000).

${ }^{31}$ F. Samavat, P. T. Ahmad, F. Mahmoodi, M. F. Samavat, and M. H. Tavakoli, Am. J. Condens. Matter Phys. 2, 73 (2012). 